\title{
DO PROJECTS REALLY END LATE? ON THE SHORTCOMINGS OF THE CLASSICAL SCHEDULING TECHNIQUES
}

\author{
Pablo Ballesteros-Pérez ${ }^{1}$ (D) Graeme D. Larsen² ${ }^{\text {ID }}$, Maria C. González-Cruz ${ }^{3}$ i \\ ${ }^{1}$ School of Architecture, Building and Civil Engineering, Loughborough University (United Kingdom) \\ ${ }^{2}$ School of the Built Environment, University of Reading (United Kingdom) \\ ${ }^{3}$ Depto. de Proyectos de Ingeniería. E.T.S.I. Industriales, UniversitatPolitècnica de València (Spain) \\ p.ballesteros@lboro.ac.uk,g.d.larsen@reading.ac.uk,mcgonzal@dpi.upv.es
}

Received August 2017
Accepted November 2017

Abstract

Many engineering projects fail to meet their planned completion dates in real practice. This is a recurrent topic in the project management literature, with poor planning and controlling practices frequently cited among the most significant causes of delays. Unfortunately, hardly any attention has been paid to the fact that the classical scheduling techniques-Gantt chart, Critical Path Method (CPM), and Program Evaluation and Review Technique (PERT) - may not be as fit for purpose as they seem. Arguably, because of their relative simplicity, these techniques are still almost the only ones taught nowadays in most introductory courses to scheduling in many engineering and management degrees. However, by utterly ignoring or inappropriately dealing with activity duration variability, these techniques provide optimistic completion dates, while suffering from other shortcomings. Through a series of simple case studies that can be developed with a few participants and common dice, a systematic critique of the classical scheduling techniques is offered. Discussion of the case studies results illustrate why limiting the contents of scheduling education and teaching can be detrimental, as the aforementioned classical scheduling techniques cannot not provide project managers with sufficient resources to effectively plan and control real projects.

Keywords - Gantt, Critical Path Method (CPM), Program Evaluation and Review Technique (PERT), Scheduling, Merge Event Bias, Project delay.

\section{Introduction}

Projects, by their very nature, need to have a defined completion date. However, in any industry, there are countless examples of projects which fail to meet their initial completion dates (e.g. Alaghbari, Kadir, Salim \& Ernawati, 2007; Gündüz, Nielsen \& Özdemir, 2013; Mahamid, Bruland \& Dmaidi, 2012; Ruqaishi \& Bashir, 2015).

This frequent problem of project delays, considering a 'delay' here as not meeting the original completion date, has been researched under multiple perspectives: economic (Yates, 1998), social (Hamzah, Khoiry, Arshad, Tawil \& Che Ani, 2011), legal (Keane \& Caletka, 2008), analytical (Alkass, Mazerolle \& Harris, 1996), programmatic (Braimah, 2014), etc., to cite just a few. Project delays have also been studied from all parties' perspectives too: contractor's (Mahamid, 2013), client's (El-Rayes \& Moselhi, 2001), government's (Orangi, Palaneeswaran \& 
Wilson, 2011), country's (Ogunlana, Promkuntong \& Jearkjirm, 1996), suppliers' (Choi \& Hartley, 1996), and workers' (Mahamid, 2013).

Given this level of research, it is perhaps surprising that even project managers who have seriously invested their time and resources in developing a feasible and reliable schedule may still find their projects end late. However, the efforts of those project managers are possibly built upon a key assumption, that the defined completion date estimated in the planning stage was accurate and achievable, at least according to the outputs of their scheduling tools. Such assumption could be forgiven, as these scheduling tools are entrench in both academia and industry, meaning the project managers perhaps learnt these during their degrees, through professional training, from fellow practitioners or just some basic texts on scheduling.

Going back to the causes of project delays, many factors have been identified: poor planning and controlling practices (Assaf \& Al-Hejij, 2006; Assaf, Al-Khalil \& Al-Hazmi, 1995), poor site management (Abdul-Rahman, Berawi, Berawi, Mohamed, Othman \& Yahya, 2006; Alaghbari et al., 2007), labor shortage and lower productivity (Odeh \& Battaineh, 2001; Sweis, Sweis, Abu Hammad \& Shboul, 2008), problems with materials supply chain and procurement (Lo, Fung \& Tung, 2006; Ballesteros-Pérez, del Campo-Hitschfeld, Mora-Melià \& Domínguez-Santos, 2015), reworks of defective units or units with insufficient quality (Ballesteros-Pérez, 2017a; Forcada, Rusiñol, Macarulla \& Love, 2014), contractor's and/or client's financial difficulties (Mansfield, Ugwu \& Doran, 1994; Ogunlana et al., 1996), design changes (Arditi, Akan \& Gurdamar, 2006; Mezher \& Tawil, 1998), poor communication and co-ordination (Fimpong \& Oluwoye, 2003), unexpected field interferences (Alarcón, Diethelm, Rojo \& Calderon, 2005), adverse weather (Ballesteros-Pérez, del Campo-Hitschfeld, González-Naranjo \& González-Cruz, 2015; Ballesteros-Pérez et al., 2017), legal disputes (Yogeswaran, Kumaraswamy \& Miller, 1998), to cite just a few. It may not be a surprise then that delays in the final completion of projects are acknowledged in many sectors as one of the most common, costly, complex, and risky problems a project manager can face (Fawzy \& El-adaway, 2012). However and quite paradoxically, among all factors that cause project delays, poor planning and controlling practices consistently stand out as an over-arching theme spanning the most frequent delay-causing problems (AlSehaimi \& Koskela, 2008).

On the other hand, classical scheduling techniques like the Gantt chart, the Critical Path Method (CPM) and the Program Evaluation and review Technique (PERT), are almost the only ones discussed in the most celebrated cross-industry Project Management standards (e.g. (APM, 2012; IPMA, 2006; PMI, 2008)). In consequence, and despite the amount of research that has been focusing on more advanced scheduling over the last decades (Ouelhadj \& Petrovic, 2009), the original versions of these techniques appear to remain the dominant scheduling norms with very few adaptations.

The Gantt chart was invented around 100 years ago, whereas CPM, and PERT were devised in the over 50 years ago. Sincethen, the Gantt chart, CPM and PERT have hardly undergone any changes, nor many other complementary scheduling methods seem to have permeated through the daily engineering and management scheduling practice (Ouelhadj \& Petrovic, 2009). This is important, as these classical techniques can exhibit serious limitations (mostly by underestimating the total or remaining project duration) for those planning and monitoring tasks for which project management practitioners use them.

This research will argue that these classical scheduling techniques have limitations and will present practical evidence on how critical their disadvantages can be, even for a project manager that tries to implement them with painstaking care. Hence, this study will shed light on an interesting dilemma: is it just that many projects end late? or, maybe, that we are (consistently and inadvertently) measuring their duration optimistically by using some scheduling tools that have serious limitations? In order to achieve this, the research will mobilize two explicit case studies where project management students (or indeed practitioners) can actively take part. The final aim is to make them understand that their training on scheduling techniques, like in many other fields, will have to continue as their careers develop. 


\section{Critical Review of the Classical Scheduling Techniques}

The Gantt chart, the CPM and the PERT will be critiqued. These are considered planning techniques, despite that they can also be used for monitoring project progress. Drawing on the scheduling literature, this section will justify and exemplify, through simple case studies aimed at students of project management scheduling, why there is a pressing need for updating the scheduling techniques many practitioners use nowadays.

\subsection{The Gantt Chart}

The Gantt chart was initially conceived as a tabular representation, and it was first described by Henry L. Gantt in a Frederick W. Taylor's paper named 'Shop Management' (Taylor 1903, pp. 1322). This technique was very well established by the mid-1920s as a general production planning tool, with a still nearly ignored use in managing projects (Wilson, 2003). It was not until the decades of the 1960s to 1980s when, along with the advent of personal computers, the task of updating the Gantt chart became less time consuming and this tool was eventually adopted among Project Managers (Wilson, 2003). Examples of simple Gantt charts are included in Figures 1 and 2.

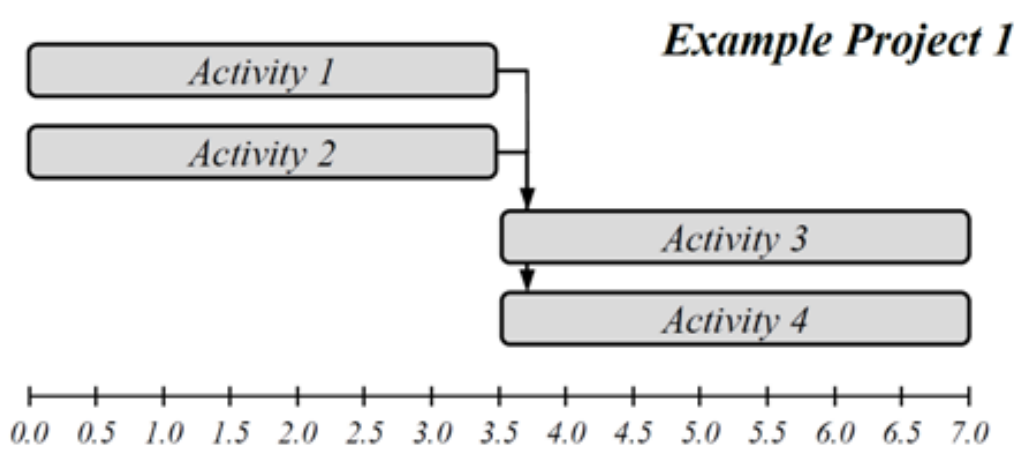

Project Duration

Legend Non critical activity Critical activity

Figure 1. Gantt chart with Critical Path representation of example project 1

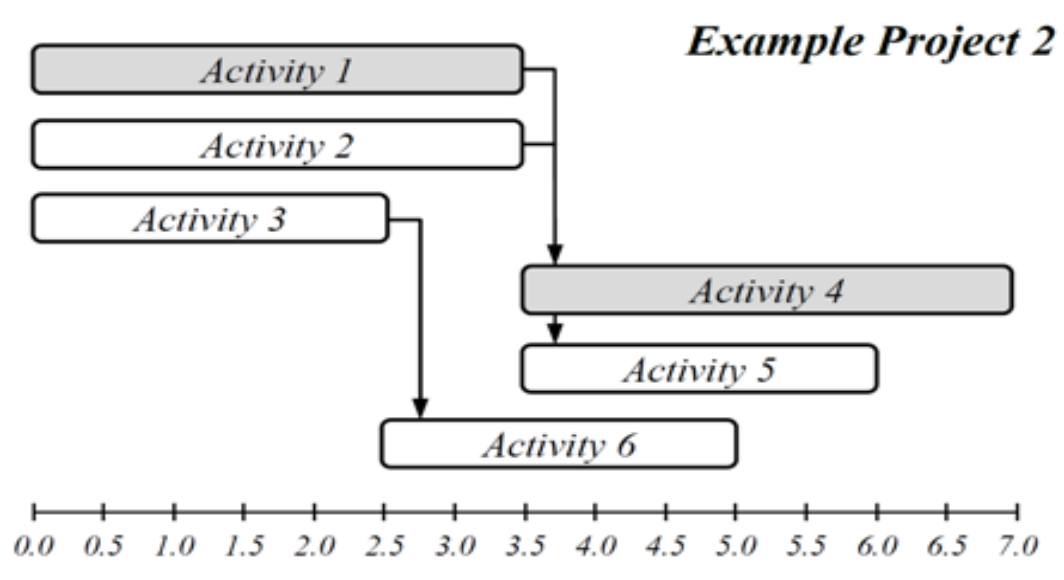

Project Duration

Legend Non critical activity Critical activity

Figure 2. Gantt chart with Critical Path representation of example project 2 
The great advantages of the Gantt chart are its simplicity, ease of understanding and that, at the time of writing, almost any scheduling software includes a Gantt chart representation tool with a straightforward interface (e.g. Microsoft Project ${ }^{\circledR}$, Oracle Primavera ${ }^{\circledR}$ ). The disadvantages are not frequently discussed in the research literature, but relevant to practitioners who use Gantt charts as the primary tool in real projects. Gantt charts have three major disadvantages.

First, the Gantt chart is a representation that promotes activity duration visualization whereas precedence relationships become much harder to appreciate. The opposite is true for network diagrams (examples for the same projects can be found in Figures 3 and 4). As an example, the project in Figure 1 represents a Gantt chart with 4 activities and the project in Figure 2 a Gantt chart with 6 activities. In both Gantt charts, the Finish-Start relationships of activities 1 and 2 with their successors are different, but it is not easy to tell apart how from the Gantt chart alone unless we see their corresponding (Activity on Node, AoN) network diagrams from Figures 3 and 4 .

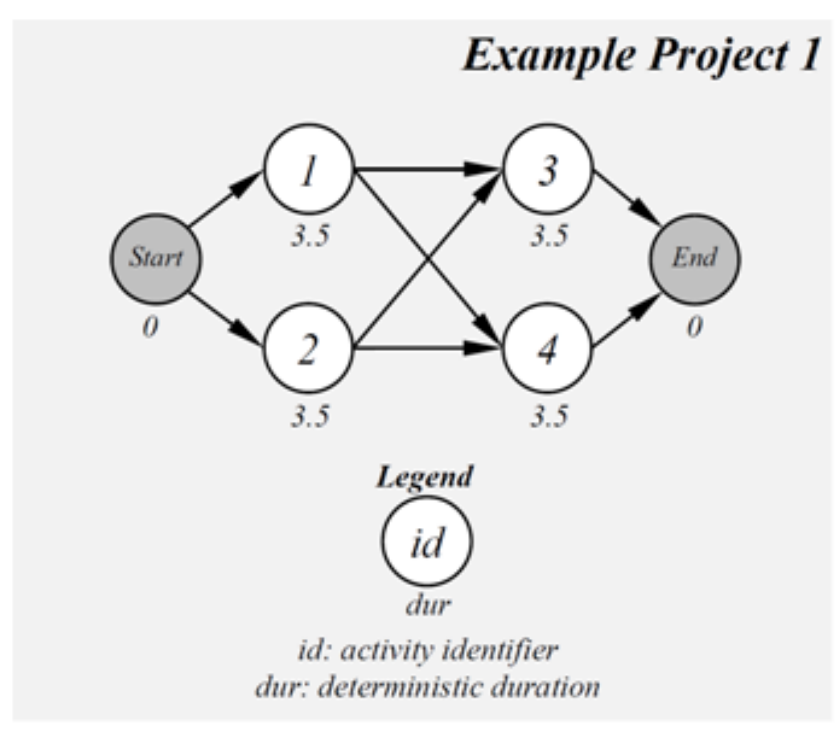

Figure 3. AoN network of the example project 1 assuming deterministic activity durations

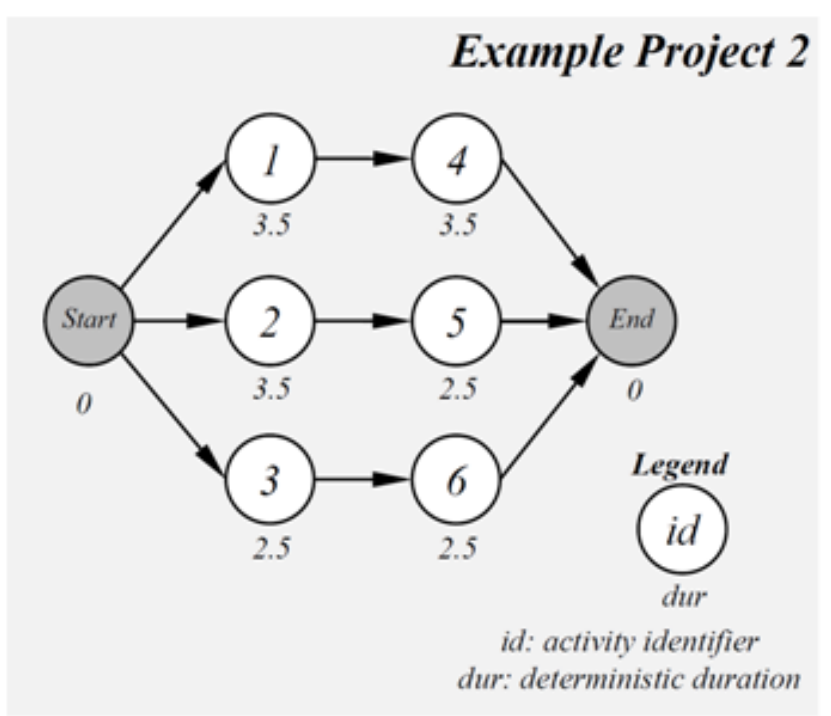

Figure 4. AoN network of the example project 2 assuming deterministic activity durations 
Relationships between activities is crucial for estimating project duration and progress, as will be proved later, not just because of the obvious functional dependence (one activity cannot start unless its predecessor finishes), but because from a 'statistical' point of view there are interesting 'side effects' when several activities merge into a single activity node/bar (e.g. the 'merge event bias' (Ballesteros-Pérez, 2017a, 2017b)). Finally, it is worth highlighting that, even in cases with a relatively small number of activities, these relationships might be very tricky to identify in a Gantt chart.

Second, and probably the biggest disadvantage of this scheduling technique, a Gantt chart only represents one possible course of events, that is, a single scenario. When carrying out any project, changes come up. For example, within a construction project the engineers might experience a lack of detailed information about the final foundation type and design. The foundations might depend on the ground conditions found after the excavations are performed across the site, together with the building design and use. The resources, time and cost are clearly very different for different foundation types and design, but a Gantt chart can only represent a single option, not two, no matter both alternatives might eventually lead to a common predecessor activity afterwards. Therefore, due to the impossibility of managing a project with multiple Gantt charts (as many as different scenarios a project might have), project schedulers just use 'one' chart, and, normally, that is either the most optimistic or what they deem as the most 'realistic' (normally a Gantt chart whose activity durations correspond to the expected average), but where the activity description might be something not very explicit (e.g., 'foundations' without describing what type of foundations those will be).

Third, linked to the point above, activity durations and costs are intrinsically variable in real-life schedules. But the Gantt chart cannot capture this variability as the bar lengths are fixed, deterministic. Indeed, because of this limitation, Gantt charts cannot include essential modelling elements like activity self-loops (an activity is likely to be repeated, normally because an unsuccessful outcome, for example a quality test). But they cannot include probabilistic alternative paths either, because under each iteration a path might have different activities being performed with different durations and/or costs.

Overall, these three limitations cause a severe loss of modeling power when trying to resemble real projects. The consequence is an optimistic appreciation of the project duration, even when average activity durations are used, as will be demonstrated later.

\subsection{The Critical Path Method (CPM)}

The CPM basically consists of identifying (and paying special attention to) the series of activities which have no slack or float at all in a project schedule. The CPM was created by Morgan R. Walker and James E. Kelley Jr. in the late 1950s (Kelley \& Walker, 1959) and they named it after the developers of the PERT technique, which was contemporary to CPM (Kelley \& Walker, 1989). This technique became widely adopted when the scheduling software included it as another attribute of the Gantt chart (Wilson, 2003).

A positive aspect of the CPM is that it corresponds to a straightforward concept: the series of (critical) activities with no slack that, if experiencing any delays, the project will run late that exact amount of time as well. But this method has three major drawbacks too.

First, one might argue that this is not a 'method' (as CPM is not a procedure itself), rather just a concept: the series of critical activities themselves the project manager need to watch closely, but nothing else. However, identifying the Critical Path in a Gantt chart where it is normally represented is not that easy, even for schedules with a small number of activities. An example can be found in Figure 2 where, despite the number of activities is just six, it is not clear whether the Critical activities are 1 and 4 or 2 and 4 .

Second, the Critical Path is a concept that makes perfect sense when two conditions are met: the scheduled activities always exist and their durations are known. These are linked to the Gantt chart limitations. Concerning the first condition, what sense does the Critical Path make in a schedule in which not all activities might happen? For example, probabilistic alternative paths (different alternative course of 
events can happen). Additionally, what relevance does the Critical Path make when some activities can self-loop one or multiple times?

Concerning the second condition, activity duration variability causes that the Critical Path can change its route through the schedule. Recent studies on work flow variability (Arashpour, Wakefield, Blismas \& Lee, 2013; Arashpour \& Arashpour, 2015) have evidenced that this variability significantly diminishes performance metrics reliability, causes inflated completion times, excessive delays, and results in productivity losses. Also, in presence of duration uncertainty, some indicators like the 'criticality Index (CI)', which measures the percentage of times in which an activity is critical, have arisen, but this has proven not to be a good predictor by itself as to how important an activity is (Vanhoucke, 2012). For example, an activity might have a $\mathrm{CI}=1$ (activity always critical), but have a very short duration variability and/or very low correlation with the project duration.

Third, the Critical Path is not a good predictor of the project duration when activities have uncertain durations, as happens in many engineering production contexts. Particularly, the Critical Path underestimates the project duration (a project can never last less than the Critical Path duration, but it usually lasts longer when activity durations are variable). This is actually the biggest limitation of the PERT too, as the latter also makes use of the Critical Path to anticipate project duration (MacCrimmon \& Ryavec, 1964). As a matter of proof, two illustrative case studies will be shown later addressing this critical limitation. Therefore, as a matter of partial conclusion, the CPM also tends to measure optimistically the project durations, that is, their completion dates.

\subsection{Program Evaluation and Review Technique (PERT)}

The PERT is a scheduling tool designed to estimate the Project Duration when activities have uncertain durations. Basically, this is achieved in two sequential stages. The first comprises the scheduler retrieving information about the Optimistic (O), most Likely $(\mathrm{L})$ and Pessimistic $(\mathrm{P})$ durations of each activity in the project schedule (also known as the 'three-point estimate' (PMI, 2008)). Only with that information it is then possible to estimate every activity mean duration $(\mu)$ and the standard deviation $(\sigma)$ by means of these simple formulae:

$$
\begin{gathered}
\mu=(O+4 L+P) / 6 \\
\sigma=(P-O) / 6
\end{gathered}
$$

The second stage involves identifying all the critical activities and with their $\mu$ and $\sigma$ values, implement the following two expressions for obtaining the average $\left(\mu_{p}\right)$ and standard deviation $\left(\sigma_{p}\right)$ of the whole project duration:

$$
\begin{gathered}
\mu_{p}=\sum_{i \in \text { critical pat }} \mu_{i} \\
\sigma_{p}=\sqrt{\sum_{i \in \text { critical pat } j} \sigma_{i}^{2}}
\end{gathered}
$$

With these two values, the PERT authors assumed that the project duration always follows a Normal distribution whose parameters are $\mu \mathrm{p}$ and $\sigma_{p}$, and with that distribution it is possible (in theory) to infer the probabilities of the project lasting any specific amount of time. Examples of Normally-distributed PERT curves will be found later in the case studies.

However, unlike the first stage of application, this second stage is commonly skipped in many introductory scheduling texts, despite it actually constitutes the true core of this technique. Evidence of this omission means there is no mention about PERT, but the three-point estimates, made in either the Project Management Body of Knowledge (PMBoK) or the International Project Management Association (IPMA) competence baseline, both of which are key Project Management standards used in both 
academia and practice. Moreover, many of these standards still improperly refer to PERT as a type of network representation (e.g. PERT networks or PERT-like networks (APM, 2012; PMI, 2008)).

Concerning its origins, PERT was developed in 1959 for measuring and controlling the progress of the Polaris Fleet Ballistic Missile (FBM) program (Malcolm, Roseboom, Clark \& Fazar, 1959), and, maybe because of its simplicity, it has undoubtedly become one of the classical Project Management tools since then. Its limitations are plenty and a research report was outsourced by the US Air Force to the Rand Corporation in 1964 due to the consistent and systematic errors that PERT was producing when forecasting and monitoring project progress. MacCrimmon and Ryavec (1964) produced a report which analyzed all PERT assumptions to find out what was really wrong with this technique. Some of the conclusions from that report will be translated here as the major disadvantages of PERT, other shortcomings have been identified more recently. Overall, three are the major limitations of PERT.

First, expressions (1) and (2) initially assume that each activity duration follows a Beta distribution despite, at a later stage the techniques makes use of the $\mu$ and $\sigma$ activity values as if they represented Normal distributions only. This happens because the PERT authors believed that the Central Limit Theorem will hold in this situation and this is not true (Hajdu \& Bokor, 2014). On top of that, even though expression (1) is quite accurate, expression (2) is not. Indeed, the accuracy of both expressions opened a long debate (Pleguezuelo, Pérez \& Rambaud, 2003) which seems to have been finally settled nowadays. Apparently, for equation (2) to be correct it has to be multiplied by a factor $\mathrm{K}$ whose expression is shown in equation (5) (Herrerías-Velasco, Herrerías-Pleguezuelo \& Van Dorp, 2011). Variables O, L and P have the same meanings as in equations 1 and 2.

$$
K=\sqrt{\frac{5}{7}+\frac{16}{7} \cdot \frac{(L-O)(P-L)}{(P-O)^{2}}}
$$

The second disadvantage, as previously outlined when discussing CPM in the presence of multiple paths, is that PERT underestimates the project duration. Moreover, it also overestimates the project duration dispersion, that is, the project duration standard deviation (MacCrimmon \& Ryavec, 1964).

This means that both expressions (3) and (4) are also incorrect. Actually, and quite unexpectedly, the PERT authors already knew this when they published their work. Malcolm et al. (1959, pp. 654) briefly mentioned "this simplification gives biased estimates such that the estimated expected time of events are always too small*" whereas the * referred to the footnote which added: "The nature of this bias is discussed in as-yet-unpublished work by C.E. Clark" (the third author of PERT). This shortcoming went un-noticed by most, despite Clark tackling the problem as thoroughly as he could and producing two brilliant papers not long afterwards (Clark, 1961, 1962). However, Clark's papers were mostly concerned with obtaining explicit analytical expressions for computing the maxima of two correlated Normal distributions, only partially addressed some of the PERT limitations. In any case, it was too late, by then the adoption of the original (but simpler) PERT was already wide despite being significantly and optimistically biased. Research argues that the analytical problem cannot be solved analytically from a statistical point of view and so far only computer simulations can provide accurate estimates (BallesterosPérez, 2017b; Banerjee \& Paul, 2008).

Finally, the third limitation of this technique is about questioning how PERT can be applied when not all the activities always happen (probabilistic alternative paths) or when some can self-loop. This would certainly require significantly complicating the PERT model, an effort that has been made at a research level (e.g. (López Martín, GarcíaGarcía, García Pérez, \& Sánchez Granero, 2012; Mehrotra, Chai, \& Pillutla, 1996; Pleguezuelo et al., 2003), but that have not reached the daily industry practice yet. 


\section{Two illustrative case studies}

After going over the major limitations of the three classical scheduling techniques, two case studies are presented. This section will demonstrate how the simple implementation of these scheduling techniques provides any project manager by default with an optimistic appreciation of the project duration. These case studies can be easily reproduced in the workplace, site production office or a classroom with students and practitioners alike.

Manual results of each case study will be eventually compared with the results of stochastic simulations that can also easily be developed by means of simple spreadsheets. Nowadays, most engineering students are familiar with the use of spreadsheets (Rafart-Serra, Bikfalvi, Soler-Masó, Prados-Carrasco \& PochGarcia, 2017), as well as with the principles of mathematical modelling (Cárcamo-Bahamonde, GómezUrgelles \& Fortuny-Aymemí, 2016) and simulation (Chen, Wei \& Li, 2016). However, description of the aforementioned simulation calculations is beyond the purpose of this manuscript. In any case, the implementation of the two suggested case studies as a class exercise will allow scheduling instructors to deliver a nice hands-on experience illustrating the classical scheduling techniques limitations, while urging their students to keep learning more advanced scheduling methods in the future.

Particularly, in order to evidence the optimistic and systematic bias that Gantt charts, CPM and PERT techniques suffer, it will be assumed, as in real-life projects, that project activity durations have some degree of variability. However, that variability will be perfectly known beforehand and modeled by the cast of dice.

The reason why activity durations need to be known and modeled properly in advance is because activity descriptions and/or durations can vary due to multiple reasons from their planning stage to their final execution (e.g. project scope changes, product requirements, etc.). However, it is not intended here that the analysis presented could be undermined by those unforeseeable variations. Hence, if we prove that even cases with 'perfect information' about activity (average and dispersion) duration, projects still end later than planned, this will be the single consequence of the scheduling techniques being flawed themselves and nothing else.

Also, the reason why these case studies use dice along with optional computer simulations is because they allow recreating the results in any training setting and that kind of hands-on experience open the eyes of the learner/student more effectively than just 'telling them'. Therefore, the main idea is to 'recreate' what a normal project manager would usually do in real-life projects and how, by doing just that, this manager will end up with an inaccurate project overview.

The first case study can be found in previous Figure 3. This was a project with 4 activities (id=1, 2, 3 and 4) and two dummy activities (with null duration and cost) which only represent the project start and finish. The duration of all the activities is always the same: 3.5 days. A quick analysis reveals that the project duration is 7 days.

However, it has been discussed that activity durations (as well as costs) are 'inherently variable', that is, we can never be certain about their exact duration (or cost). That is why, we will assume now that our real activity durations will be modeled, for example, by the cast of a die as in Figure 5. It is clear then that the project in Figure 5 might last from a minimum of 2 days up to a maximum of 12 days. 


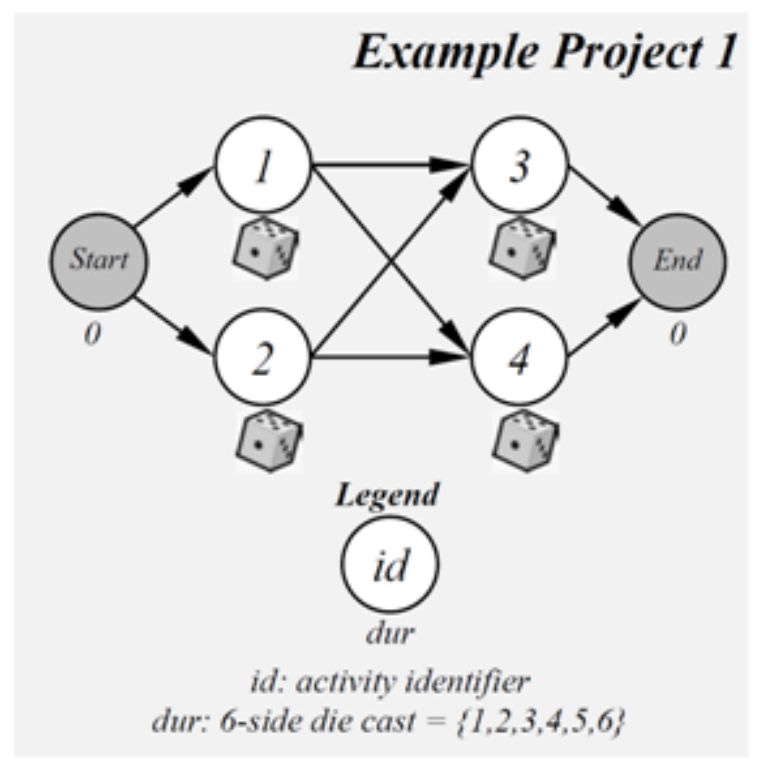

Figure 5. AoN network of the example project 1 assuming variable activity durations

Theoretically, at least from the project manager's perspective, nothing has changed. The magnitude 3.5 corresponds to the average of a six-sided die, so this project, on average, should still last 7 days. The question is, will this 'realistic' schedule ('realistic' because its activity durations coincide with an average six-sided die cast) really last 7 days?

To answer this question many project managers would resort to a Gantt chart at first instance and represent the Critical path in it. The result of that action was already shown in Figure 1. Now our project manager feels reassured: that Gantt chart with four possible Critical Paths (1-3, 1-4, 2-3, 2-4) says that the project will last, indeed, 7 days. But, will it?

Now it is the moment to ask four participants to cast one die each multiple times. The Project Duration will correspond to the maximum of participants 1's and 2's dice plus the maximum of participants 3's and 4's dice in every simulation (every time the four participants cast their dice once). After several simulations, it is surprising how infrequently we have a project duration equal or below 7 , when this was expected to happen at least on $50 \%$ of the occasions.

Furthermore, this case study has applied the Gantt chart and the CPM, but it is also possible to implement the PERT calculations now that we are dealing with variable activity durations. The results are shown in Figure 6. 


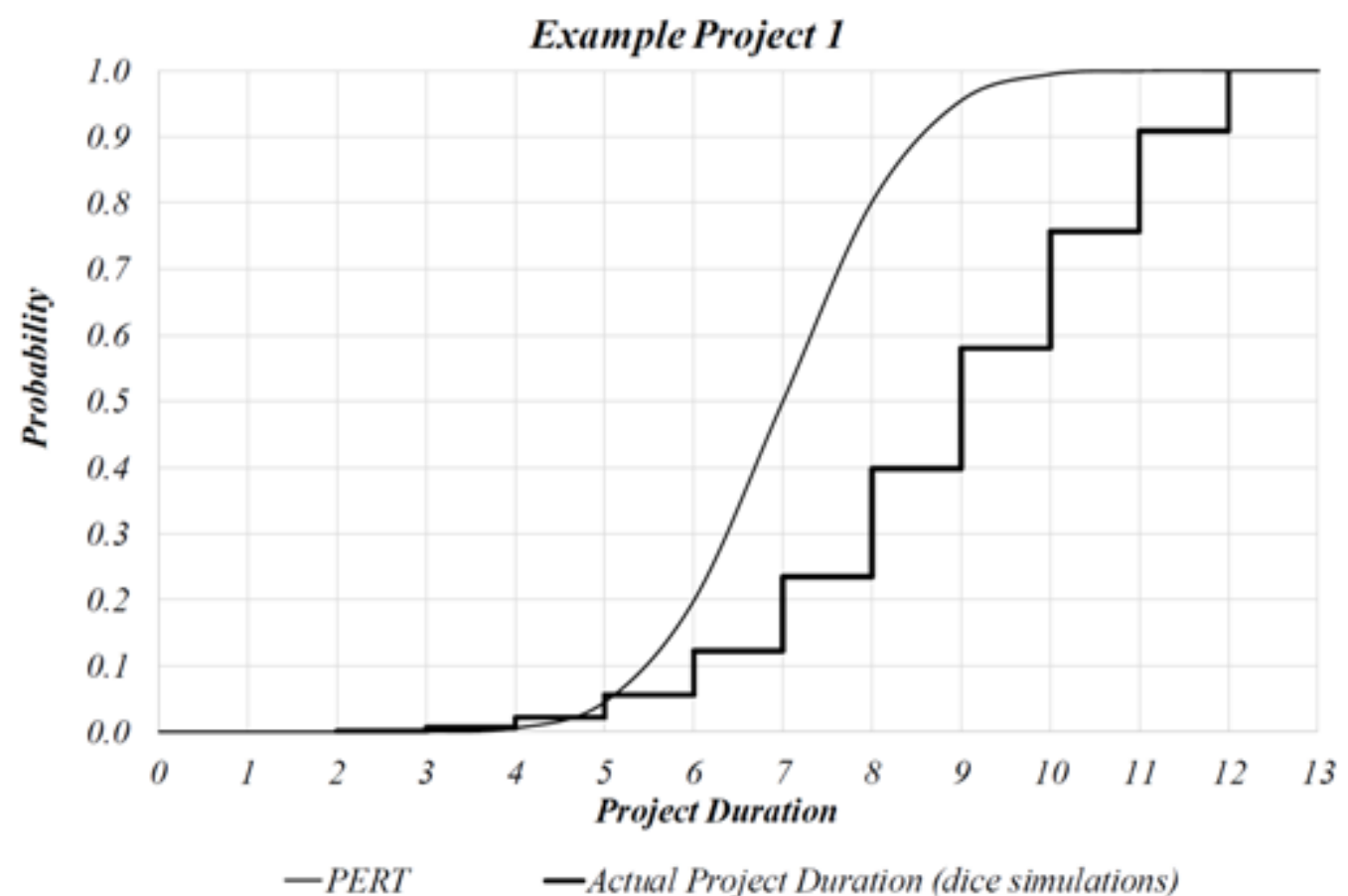

Figure 6. PERT project duration estimation versus the Actual one for Example Project 1

From the probabilistic Cumulative Distribution Function (CDF) curve (the one to the right) representing the 'Actual Project Duration' it becomes quite clear that, on average (50\% probability), this project is going to last 9 days ( 8.96 to be exact), not 7 days. This is indeed $28 \%$ longer than expected (more than 3 months in a year), and that is just 'on average'. Additionally, only approximately $23 \%$ of the cases will have a duration of 7 days or less, which was unexpected as well.

However, this case study, despite basically representing a simplified and small set of nodes, also represents frequent sub-projects/work components of bigger projects. This means that, every time a bigger project has a similar set of nodes, the complete project will experience a (relative) delay at that point. Accumulation of multiple nodes like these will eventually cause significant delays. However, the case study exemplified is not an exception.

The second case study adopts a different topology (network structure) as in Figure 4. This project involves six activities in three different paths, but in this case, we will be purposefully subtracting 1 day from activity 5 (the second path) and one day from activities 3 and 6 (the third path). Therefore, activities 3, 5 and 6 last 2.5 days now, instead of 3.5, and this way there is a dominant Critical Path which is materialized by activities 1 and 4 . Again, the participants are shown Figure 4 first to show them the basic project (deterministic) schedule. Then, they are told that activity durations are to be modeled by six-sided dice too. The activity durations will be now as represented in Figure 7. 


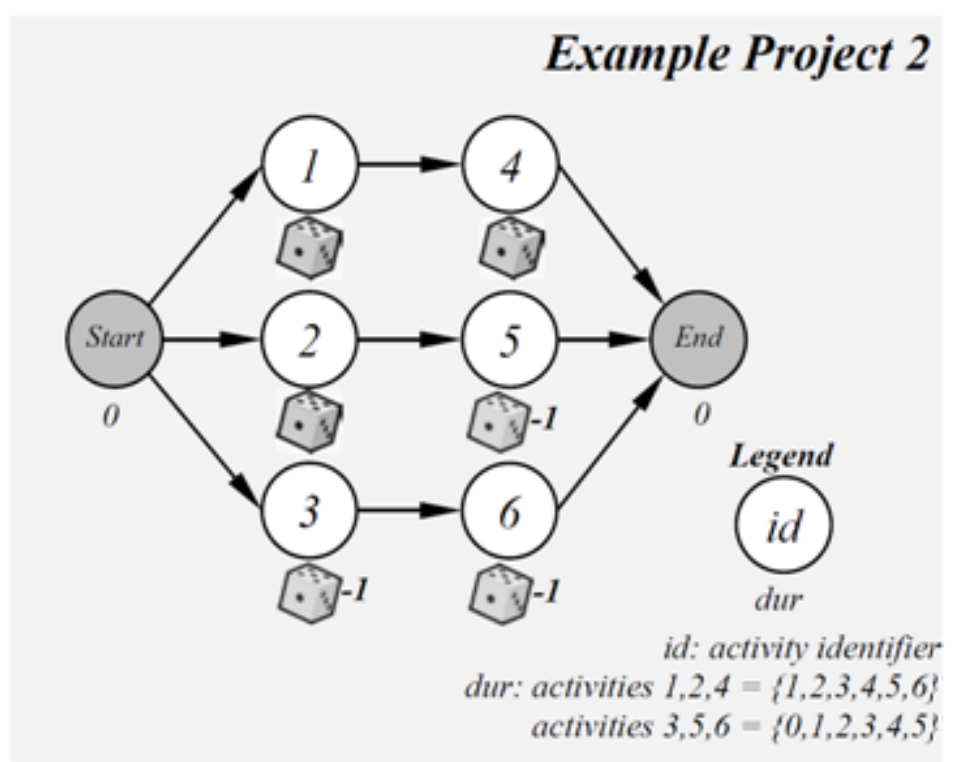

Figure 7. AoN network of the example project 2 assuming variable activity durations

As in case study one, the participants are exposed first to the Gantt chart with the critical path that any scheduler would develop to forecast this project 'average' duration. That was formerly presented in Figure 2.

At this stage, we can pick six participants but we tell them that when they cast their dice, participants 3, 5 and 6 will need to subtract one unit. The project duration will be the maximum among the sum of participants 1's and 4's, 2's and 5's (minus 1), and 3's and 6's (minus 2). The result, despite now we have a clearer critical path, is still surprising. The project hardly ever lasts 7 days or less. Figure 8 shows the real results while comparing them against the PERT forecast.

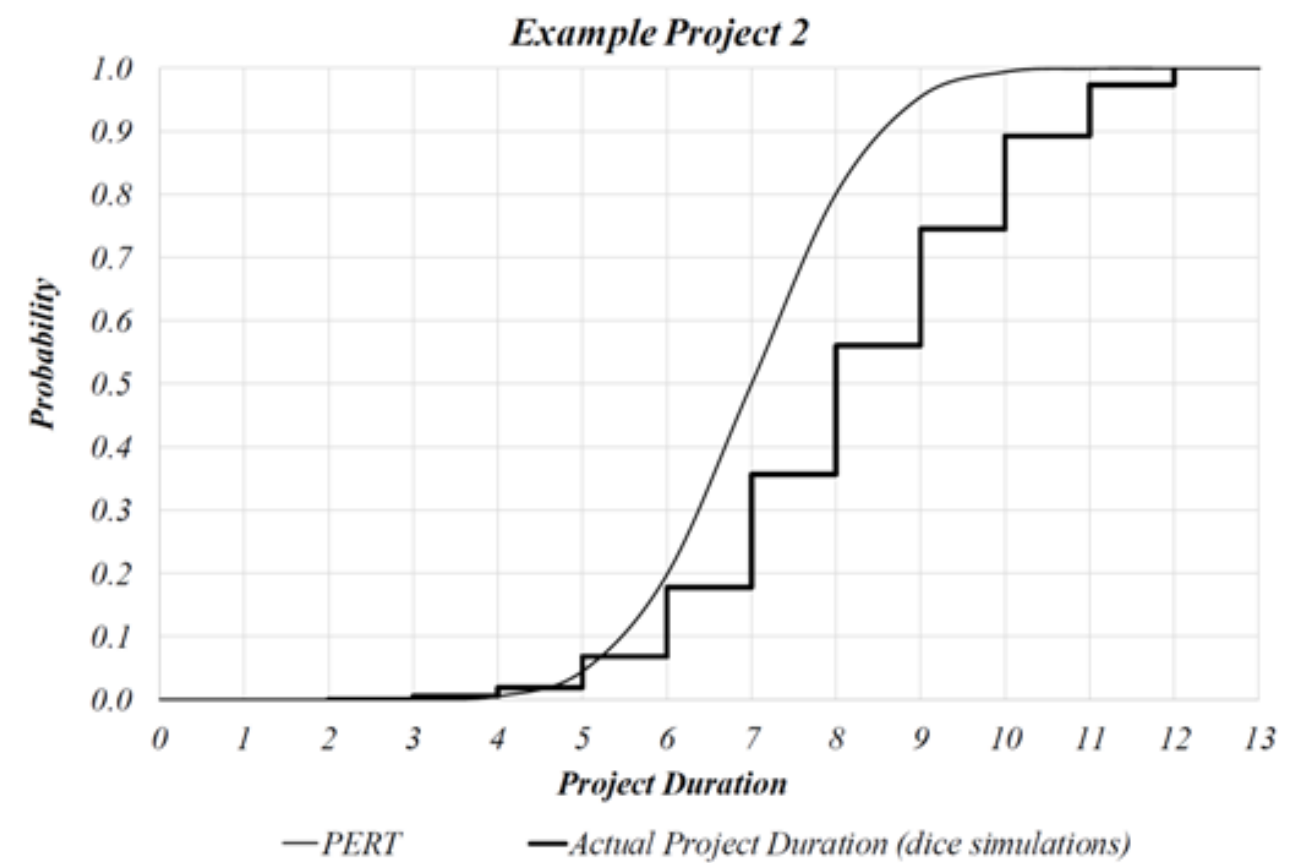

Figure 8. PERT project duration estimation versus the Actual one for Example Project 2 
The average duration of this project is 8 days ( 8.22 to be exact), which represents an average extension of $17.5 \%$ (more than two months in one year). Indeed, a project duration of 7 or fewer days will only be achieved in a third of the occasions.

All this is the consequence of a phenomenon known as the 'merge (event) bias' (Douglas, 1978; Lu, 2002; Pontrandolfo, 2000). This phenomenon occurs when multiple paths converge into a single node (activity). In short, the merge bias causes that the current average project duration up to an activity with multiple predecessors can no longer be calculated as the average of the longest (critical) incoming path. Instead, the 'maximum' of all the incoming paths durations has the be assumed. In other words, this means that the average total project duration cannot be simply computed as the sum (convolution) of distributions, and this makes the Central Limit Theorem and the assumption of Normality, untenable.

To sum up, in presence of activities with variable durations (virtually always in real-life projects), the probabilities of at least one path taking longer than anticipated grows with the number of paths and also when the path durations are close to each other. However, currently business and project models point toward working on multiple simultaneous tasks as the norm. A good project manager always tries to make the most of the resources available. Therefore, when a Project Manager finds that one path (sequence of activities) needs more resources, more resources will be transferred to those activities in order to progress faster. The latter means that, in real projects, it is indeed quite normal to have multiple paths with similar durations. This means that these two case studies represent what happens at the 'atomic level' of many other bigger project schedules, and every time this happens, the overall project duration cumulates small delays.

Therefore, what we have represented here reflects what is happening over and over again in real projects, and despite the case studies extreme simplicity, none of the three classical scheduling techniques, even after feeding them with perfect activity information, has been able to anticipate the likely project delays.

\section{Conclusions}

The major limitations of the classical scheduling techniques: the Gantt chart, the CPM, and the PERT, have been reviewed and exemplified. Particularly, the commonly accepted advantages of the three techniques are their simplicity, ease of understanding and that at the time of writing most scheduling software implement them with straightforward user interfaces. However, their disadvantages can, and usually are, critical.

Activity precedence relationships represented on Gantt charts (e.g. Finish-Start, Finish-Finish, Start-Start and Start-Finish, with or without time lags) are generally difficult to appreciate when the number of activities grows. Also, Gantt charts activity durations are deterministic and can only show one possible course of events. Finally, advanced activity or path modelling possibilities (e.g. probabilistic alternative or complementary paths of events, single or multiple activity self-loops) cannot be accommodated in Gantt charts either. As these advanced modelling elements are usually necessary when dealing with some degree of scheduling uncertainty, its absence in Gantt charts are very limiting.

Analogously, the CPM is quite difficult to grasp when not all activities in a schedule can happen (e.g. again when there are possible and/or alternative course of events), and/or when the activities can be repeated (self-loop). Furthermore, the CPM provides the project manager with optimistic project duration estimations unless all activities are in perfect series (one after the other with no parallel paths). However, as this latter condition is not fulfilled in hardly any real project, the CPM will always tend to underestimate the projects duration.

The PERT, on the other hand, despite being the only technique allowing for activity duration variability, makes use of an incorrect set of assumptions and formulas plus an unfortunate choice of statistical distributions. Overall, the result is that PERT underestimates the projects duration, like the CPM and Gantt charts do, but additionally it also overestimates the project duration standard deviation. 
However, these techniques are still used today by many engineering practitioners and project managers as they are the most referenced scheduling tools by core Project Management standards (e.g. PMBoK, IPMA competence Baseline, APMBoK). Also, they are the most preferred tools by the most celebrated Project Management software (e.g. Microsoft Project ${ }^{\circledR}$, Oracle Primavera ${ }^{\circledR}$ ). All the same, without exception, by neglecting or not properly dealing with activity duration variability among other critical issues, project duration planning and monitoring tasks are optimistically and significantly biased.

In order to evidence these limitations, two case studies that can be reproduced by students or practitioners in any teaching environment have been developed. Through the cast of simple six-sided dice, the participants can simulate the activity durations variability of any project. However, even for these cases when the project manager counts on perfect information beforehand (as it is known that all activity durations are following Discrete Uniform distributions with six equally likely outcomes), the three scheduling techniques have failed to produce reliable project duration estimates. Indeed, these case studies that represent small sets of activities constitute, nonetheless, a close replica of the smaller components of bigger projects. This, as bigger projects also experience small cumulative delays every time two or more activities with duration variability converge into a single node.

The influence of this unaccounted duration variability is different for each industry, though. The manufacturing industry, in general, tend to work indoors (lower climate influence), with semi-repetitive products (higher opportunity of learning from the past), with relatively stable project teams and clients. This might limit the activity duration variability and, hence, cause a lower impact of the optimistic biases described here. However, on the other side of this spectrum, we can find the example of the construction and shipbuilding industries. Construction and Shipbuilding project managers need to deliver projects with more variable conditions (works are carried out mostly outdoors, they are generally unique, constant changes in project team is the norm, variable project locations, among others). Variability is much higher and the previous technique biases are even more pronounced. It may not be a surprise after all, that construction projects, for instance, have traditionally been one of the sectors suffering more from missing their original completion dates.

Therefore, the limitations embedded in the classical scheduling techniques that may form part of the introductory (and sometimes the only) lessons of scheduling courses in engineering and management degrees (and beyond within the work place), need to be seriously reconsidered. Many agents can take part in this process: universities by ensuring an objective account of the methods is always taught (covering advantages and disadvantages), the professional bodies with the tools they promote, the software developers by shifting to more advanced (stochastic) scheduling techniques with affordable prices, even, public and private companies with the tools they implement and require from contractors.

There are already other alternative scheduling techniques that any practitioner can embrace and which would produce a more reliable project duration and progress forecasts (e.g. Schedule Risk Analysis, Critical Chain Management). These alternative techniques are not significantly harder to implement, but even if they were, it is imperative that students and practitioners alike start to consider them if they want to start managing projects more effectively and more efficiently.

\section{Declaration of Conflicting Interests}

The authors declared no potential conflicts of interest with respect to the research, authorship, and/or publication of this article.

\section{Funding}

This work was supported by the CIOB Bowen Jenkins Legacy Research Fund under Grant number BLJ2016/BJL.01 at the University of Reading (United Kingdom) 


\section{References}

Abdul-Rahman, H., Berawi, M. A., Berawi, A.R., Mohamed, O., Othman, M., \& Yahya, I.A. (2006). Delay Mitigation in the Malaysian Construction Industry. Journal of Construction Engineering and Management, 132(2), 125-133. https://doi.org/10.1061/(ASCE)0733-9364(2006)132\%3A2(125)

Alaghbari, W., Kadir, M.R.A., Salim, A., \& Ernawati (2007). The significant factors causing delay of building construction projects in Malaysia. Engineering, Construction and Arcbitectural Management, 14(2), 192206. https://doi.org/10.1108/09699980710731308

Alarcón, L.F., Diethelm, S., Rojo, O., \& Calderon, R. (2005). Assessing the impacts of implementing lean construction. Proc., Int. Group for Lean Construction Annual Conf., Group for Lean Construction. Sydney, Australia (pp. 387-393).

Alkass, S., Mazerolle, M., \& Harris, F. (1996). Construction delay analysis techniques. Construction Management and Economics, 14(5), 375-394. https://doi.org/10.1080/014461996373250

AlSehaimi, A., \& Koskela, L. (2008). What Can be Learned from Studies on Delay in Construction? Proceedings for the 16th Annual Conference of the International Group for Lean Construction, 95-106.

APM (2012). Association for Project Management Body of Knowledge. 6th edition. High Wycombe, United Kingdom: Association for Project Management.

Arashpour, M., \& Arashpour, M. (2015). Analysis of Workflow Variability and Its Impacts on Productivity and Performance in Construction of Multistory Buildings. Journal of Management in Engineering, 31(6), 4015006. https://doi.org/10.1061/(ASCE)ME.1943-5479.0000363

Arashpour, M., Wakefield, R., Blismas, N., \& Lee, E. (2013). A new approach for modelling variability in residential construction projects. Australasian Journal of Construction Economics and Building, 13(2), 83. https://epress.lib.uts.edu.au/journals/index.php/AJCEB/article/view/3120 https://doi.org/10.5130/ajceb.v13i2.3120

Arditi, D., Akan, G.T., \& Gurdamar, S. (2006). Reasons for delays in public projects in Turkey. Construction Management and Economics, 3(2), 171-181. E. \& F.N. Spon Ltd. https://doi.org/10.1080/01446198500000013

Assaf, S.A., \& Al-Hejji, S. (2006). Causes of delay in large construction projects. International Journal of Project Management, 24(4), 349-357.https://doi.org/10.1016/j.ijproman.2005.11.010

Assaf, S.A., Al-Khalil, M., \& Al-Hazmi, M. (1995). Causes of Delay in Large Building Construction Projects. Journal of Management in Engineering, 11(2), 45-50. https://doi.org/10.1061/(ASCE)0742597X(1995)11:2(45)

Ballesteros-Pérez, P. (2017a). Modelling the boundaries of project fast-tracking. Automation in Construction, 84, 231-241. https://doi.org/10.1016/j.autcon.2017.09.006

Ballesteros-Pérez, P. (2017b). M-PERT. A manual project duration estimation technique for teaching scheduling basics. Journal of Construction Engineering and Management, 143(9), 4017063.

https://doi.org/10.1061/(ASCE)CO.1943-7862.0001358

Ballesteros-Pérez, P., del Campo-Hitschfeld, M.L., González-Naranjo, M.A., \& González-Cruz, M.C. (2015). Climate and construction delays: Case study in Chile. Engineering, Construction and Architectural Management, 22(6), 596-621. https://doi.org/10.1108/ECAM-02-2015-0024

Ballesteros-Pérez, P., del Campo-Hitschfeld, M. L., Mora-Melià, D. \& Domínguez, D. (2015). Modeling bidding competitiveness and position performance in multi-attribute construction auctions. Operations Research Perspectives, 2, 24-35. https://doi.org/10.1016/j.orp.2015.02.001

Ballesteros-Pérez, P., Rojas-Céspedes, Y.A., Hughes, W., Kabiri, S., Pellicer, E., Mora-Melià, D. et al. (2017) Weather-wise: A weather-aware planning tool for improving construction productivity and dealing with claims. Automation in Construction, 84, 81-95. https://doi.org/10.1016/j.autcon.2017.08.022

Banerjee, A., \& Paul, A. (2008). On path correlation and PERT bias. European Journal of Operational Research, 189(3), 1208-1216. https://doi.org/10.1016/j.ejor.2007.01.061 
Braimah, N. (2014). Understanding Construction Delay Analysis and the Role of Preconstruction Programming. Journal of Management in Engineering, 30(5), 4014023.

https://doi.org/10.1061/(ASCE)ME.1943-5479.0000216

Chen, B., Wei, L., \& Li, H. (2016) Teaching complicated conceptual knowledge with simulation videos in foundational electrical engineering courses. Journal of Technology and Science Education, 6(3), 148-165. https://doi.org/10.3926/jotse.174

Choi, T.Y., \& Hartley, J.L. (1996). An exploration of supplier selection practices across the supply chain. Journal of Operations Management, 14(4), 333-343. https://doi.org/10.1016/S0272-6963(96)00091-5

Clark, C.E. (1961). The Greatest of a Finite Set of Random Variables. Operations Research, 9(2), 145-162. INFORMS. https://doi.org/10.1287/opre.9.2.145

Clark, C.E. (1962). Letter to the Editor-The PERT Model for the Distribution of an Activity Time. Operations Research, 10(3), 405-406. doi: 10.1287/opre.10.3.405. https://doi.org/10.1287/opre.10.3.405

Cárcamo-Bahamonde, A.D., Gómez-Urgelles, J.V., \& Fortuny-Aymemí J.M. (2016) Mathematical modelling in engineering: A proposal to introduce linear algebra concepts. Journal of Technology and Science Education, 6(1), 62-70. https://doi.org/10.3926/jotse.177

Douglas, D.E. (1978). PERT and simulation. WSC '78 Proceedings of the 10th conference on Winter simulation (10, 89-98). IEEE.

El-Rayes, K., \& Moselhi, O. (2001). Impact of Rainfall on the Productivity of Highway Construction. Journal of Construction Engineering and Management, 127(2), 125-131. https://doi.org/10.1061/(ASCE)07339364(2001)127:2(125)

Fawzy, S.A., \& El-adaway, I.H. (2012). Contract Administration Guidelines for U.S. Contractors Working under World Bank-Funded Projects. Journal of Legal Affairs and Dispute Resolution in Engineering and Construction, 4(2), 40-50. https:// doi.org/10.1061/(ASCE)LA.1943-4170.0000088

Fimpong, Y., \& Oluwoye, J. (2003). Significant factors causing delay and cost overrun in construction of groundwater projects in Ghana. Construction Research, 1(2), 175-187.

https://doi.org/10.1142/S1609945103000418

Forcada, N., Rusiñol, G., Macarulla, M., \& Love, P.E.D. (2014). Rework in highway projects. Journal of Civil Engineering and Management, 20(4), 445-465. https://doi.org/10.3846/13923730.2014.893917

Gündüz, M., Nielsen, Y., \& Özdemir, M. (2013). Quantification of Delay Factors Using the Relative Importance Index Method for Construction Projects in Turkey. Journal of Management in Engineering, 29(2), 133-139. https://doi.org/10.1061/(ASCE)ME.1943-5479.0000129

Hajdu, M., \& Bokor, O. (2014). The Effects of Different Activity Distributions on Project Duration in PERT Networks. Procedia-Social and Behavioral Sciences, 119, 766-775.

https://doi.org/10.1016/j.sbspro.2014.03.086

Hamzah, N., Khoiry, M.A., Arshad, I., Tawil, N.M., \& Che Ani, A.I. (2011). Cause of Construction Delay - Theoretical Framework. Procedia Engineering, 20, 490-495. https://doi.org/10.1016/j.proeng.2011.11.192

Herrerías-Velasco, J.M., Herrerías-Pleguezuelo, R., \& Van Dorp, J.R. (2011). Revisiting the PERT mean and variance. European Journal of Operational Research, 210(2), 448-451.

https://doi.org/10.1016/j.ejor.2010.08.014

IPMA (2006). ICB-IPMA Competence Baseline version 3.0. International Project Management Association (IPMA), Nijkerk, The Netherlands.

Keane, P.J., \& Caletka, A.F. (2008). Delay analysis in construction contracts. Oxford, U.K: Wiley-Blackwell. https://doi.org/10.1002/9781444301144

Kelley, J., \& Walker, M. (1959). Critical-Path Planning and Scheduling. Proceedings of the Eastern Joint Computer Conference. https://doi.org/10.1145/1460299.1460318

Kelley, J., \& Walker, M. (1989). The Origins of CPM: A Personal History. PMNETwork, 3(2), 7-22. 
Lo, T.Y., Fung, I.W., \& Tung, K.C. (2006). Construction Delays in Hong Kong Civil Engineering Projects. Journal of Construction Engineering and Management, 132(6), 636-649. https://doi.org/10.1061/(ASCE)07339364(2006)132\%3A6(636)

López Martín, M.M., García García, C.B., García Pérez, J., \& Sánchez Granero, M.A. (2012). An alternative for robust estimation in Project Management. European Journal of Operational Research, 220(2), 443-451. https://doi.org/10.1016/j.ejor.2012.01.058

Lu, M. (2002). Enhancing Project Evaluation and Review Technique Simulation through Artificial Neural Network-based Input Modeling. Journal of Construction Engineering and Management, 128(5), 438-445. https://doi.org/10.1061/(ASCE)0733-9364(2002)128\%3A5(438)

MacCrimmon, K.R., \& Ryavec, C.A. (1964). An Analytical Study of the PERT Assumptions. Operations Research, 12(1), 16-37. https://doi.org/10.1287/opre.12.1.16

Mahamid, I. (2013). Contractors perspective toward factors affecting labor productivity in building construction. Engineering, Construction and Architectural Management, 20(5), 446-460. https://doi.org/10.1108/ECAM-08-2011-0074

Mahamid, I., Bruland, A., \& Dmaidi, N. (2012). Causes of Delay in Road Construction Projects. Journal of Management in Engineering, 28(3), 300-310. https://doi.org/10.1061/(ASCE)ME.1943-5479.0000096

Malcolm, D.G., Roseboom, J.H., Clark, C.E., \& Fazar, W. (1959). Application of a Technique for Research and Development Program Evaluation. Operations Research, 7(5), 646-669.

https://doi.org/10.1287/opre.7.5.646

Mansfield, N., Ugwu, O., \& Doran, T. (1994). Causes of delay and cost overruns in Nigerian construction projects. International Journal of Project Management, 12(4), 254-260. https://doi.org/10.1016/02637863(94)90050-7

Mehrotra, K., Chai, J., \& Pillutla, S. (1996). A study of approximating the moments of the job completion time in PERT networks. Journal of Operations Management, 14(3), 277-289. https://doi.org/10.1016/02726963(96)00002-2

Mezher, T.M., \& Tawil, W. (1998). Causes of delays in the construction industry in Lebanon. Engineering, Construction and Architectural Management, 5(3), 252-260. https://doi.org/10.1108/eb021079

Odeh, A.M., \& Battaineh, H.T. (2001). Causes of construction delay: Traditional contracts. International Journal of Project Management, 20(1), 67-73. https://doi.org/10.1016/S0263-7863(00)00037-5

Ogunlana, S.O., Promkuntong, K., \& Jearkjirm, V. (1996). Construction delays in a fast-growing economy: Comparing Thailand with other economies. International Journal of Project Management, 14(1), 37-45. https://doi.org/10.1016/0263-7863(95)00052-6

Orangi, A., Palaneeswaran, E., \& Wilson, J. (2011). Exploring Delays in Victoria-Based Astralian Pipeline Projects. Procedia Engineering, 14, 874-881. https://doi.org/10.1016/j.proeng.2011.07.111

Ouelhadj, D., \& Petrovic, S. (2009). A survey of dynamic scheduling in manufacturing systems. Journal of Scheduling, 12(4), 417-431. https://doi.org/10.1007/s10951-008-0090-8

Pleguezuelo, R.H., Pérez, J.G., \& Rambaud, S.C. (2003). A note on the reasonableness of PERT hypotheses. Operations Research Letters, 31(1), 60-62. https://doi.org/10.1016/S0167-6377(02)00151-7

PMI (2008). A Guide to the Project Management Body of Knowledge (5th edition). (P. M. I. N. square. USA, Ed.). Newton square, USA: Project Management Institute.

Pontrandolfo, P. (2000). Project duration in stochastic networks by the PERT-path technique. International Journal of Project Management, 18, 215-222. https://doi.org/10.1016/S0263-7863(99)00015-0

Rafart-Serra, M.A., Bikfalvi, A., Soler-Masó, J., Prados-Carrasco, F., \& Poch-Garcia, J. (2017) Improving the learning experience of business subjects in engineering studies using automatic spreadsheet correctors. Journal of Technology and Science Education, 7(2), 203-220. https://doi.org/10.3926/jotse.252

Ruqaishi, M., \& Bashir, H.A. (2015). Causes of Delay in Construction Projects in the Oil and Gas Industry in the Gulf Cooperation Council Countries: A Case Study. Journal of Management in Engineering, 31(3), 5014017. https://doi.org/10.1061/(ASCE)ME.1943-5479.0000248 
Sweis, G., Sweis, R., Abu Hammad, A., \& Shboul, A. (2008). Delays in construction projects: The case of Jordan. International Journal of Project Management, 26(6), 665-674.

https://doi.org/10.1016/j.ijproman.2007.09.009

Taylor, F.W. (1903). Shop Management. ASME Transactions, 24, 1337-1480.

Vanhoucke, M. (2012). Project Management with Dynamic Scheduling. Berlin, Heidelberg: Springer Berlin Heidelberg. https://doi.org/10.1007/978-3-642-25175-7

Wilson, J. M. (2003). Gantt charts: A centenary appreciation. European Journal of Operational Research, 149(2), 430-437. https://doi.org/10.1016/S0377-2217(02)00769-5

Yates, D.J. (1998). Conflict and disputes in the development process: A transaction cost economics perspective. Pacific Rim Property Research Journal Proceedings (pp. 1-14).

Yogeswaran, K., Kumaraswamy, M.M., \& Miller, D.R.A. (1998). Claims for extensions of time in civil engineering projects. Construction Management and Economics, 16(3), 283-293.

https://doi.org/10.1080/014461998372312

Published by OmniaScience (www.omniascience.com)

Journal of Technology and Science Education, 2018 (www.jotse.org)

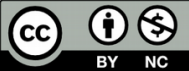

Article's contents are provided on an Attribution-Non Commercial 4.0 Creative commons International License.

Readers are allowed to copy, distribute and communicate article's contents, provided the author's and JOTSE journal's names are included. It must not be used for commercial purposes. To see the complete licence contents, please visit https://creativecommons.org/licenses/by-nc/4.0/. 